\title{
CORRIGENDUM
}

\section{Regions of homozygosity in three Southeast Asian populations}

\author{
Shu-Mei Teo, Chee-Seng Ku, Agus Salim, Nasheen Naidoo, Kee-Seng Chia and Yudi Pawitan
}

Journal of Human Genetics (2012) 57, 400; doi:10.1038/jhg.2012.51

Correction to: Journal of Human Genetics (2012) 57, 101-108; doi:10.1038/jhg.2011.132; published online 1 December 2011

The authors of the above article noted an error in publication of this paper in Figure 1. The correct figure is shown below.

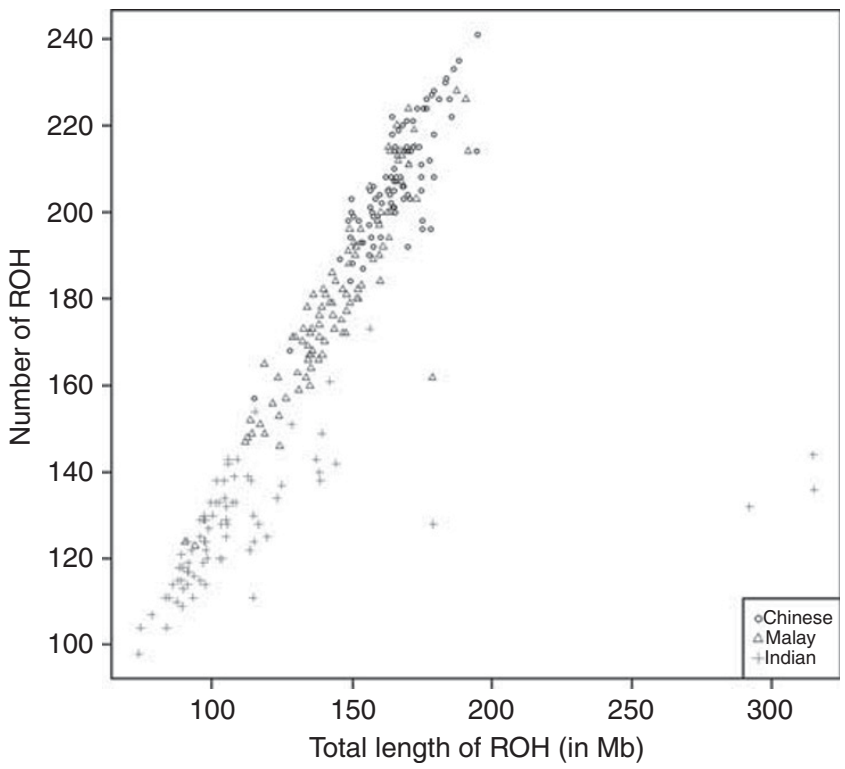

Figure 1 Number of $\mathrm{ROH}$ versus total length of $\mathrm{ROH}$ in each individual.
The authors would like to apologize for the error. This correction does not affect the rest of the results and their interpretation as discussed in the paper. 